\title{
Pengaruh Kosep Desain (Eksterior dan Interior), Excellent Service, dan Penetapan Harga Toko yang Bernuansa Islam Mempengaruhi Minat Belanja Konsumen Muslim dalam Kegiatan Perspektif Hukum Ekonomi Syariah
}

\section{Fitria Sofiana \\ Isma Swadjadja}

e-mail: opiunyu25@gmail.com

\begin{abstract}
Buying consumer interest is the seller must be able to sell a good impression has not sold the goods, the impression that can shape the image of his shop, this has been put forward by Sutisna (2001) in his book Consumer Behavior: Theory and Applications that storeatmosphere (shop atmosphere) will also determine the image of the store itself. If the store features comfortable, air-conditioned, and artistic arrangements for the use of attractive wall paint, all show that the mood of the store is able to increase the luxury and high business competitiveness.

From the results of this study, the factors that influence the next decision is the excellent service (excellent service) factors that affect interest. Based on questions about comfort ditoko sakinah perceived by consumers. The service and convenience provided by the sakinah store is considered good by consumers but has not had a major impact in influencing buying interest. By providing a convenient waiting room or shofa facility for customers who are trying sakinah. Thus, customers will feel cared for and happy to re-purchase at a sakinah shop and pricing. Price determination based on the question of the respondent's price level agrees with the price paid in accordance with the quality of the sakinah product. Thus, the company must determine the price in accordance with product quality in order to compete with other companies. In addition, companies can provide discounts or discounts to attract consumers more, so as to improve purchasing decisions sakinah.

From the results of this study the method used is Quantitative Design (exterior and interior) has a contribution of 63.3\% together to the dependent variable $(Y)$ ie consumer spending interest. The remaining $36.7 \%$ is influenced by other factors that are Excellent service and Price Pricing and which are not included in the research.

With study research conducted in store Sakinah Wonorejo area of West Surabaya. From the store then the value of increased interest obtained the influence in forming other variables such as excellent service, pricing.
\end{abstract}

Keywords: Design (exterior and interior), Excellent Service, Pricing and Interest 


\section{PENDAHULUAN}

Pertumbuhan usaha retail di Indonesia menurut pelaksana harian Asosiasi Pengusaha Retail Indonesia (APRINDO), Roy menuturkan bahwa pertumbuhan retail di tahun 2015-2016 mencapai 8-10\%, maka kemungkina di tahun 2017 mengalami pertumbuhan digit. Estimasi pertumbuhan retail yang mencapai $12 \%$ pada tahun tersebut dapat dicapai atas dorongan sektor konsumsi barang kebutuhan sehari-hari.

Penelitia yang dipaparkan sebelumnya, bahwa pelayanan mampu memepengaruhi minat belanja konsumen. Menurut Engel dan Miniard (dalam Pramono, 2012) ${ }^{1}$ Excellent Service dan kepuasan sesudah transaksi merupakan salah satu alasan mengapa konsumen tertarik untuk memilih suatu produk atau dengan kata lain, Excellent Service menjadi daya tarik dari suatu produk dan Excellent Service mempunyai sumbangan penting terhadap keberhasilan produk dalam bersaing di pasar. Excellent Service dalam sebuah muamalah diperlukan oleh perusahaan untuk menjaga citra baik produk, merek dagang, dan citra perusahaan atau produsen.

Islam juga memperbolehkan umat untuk menikmati konsumsi barang dan jasa yang dihalalkan di luar kebutuhan primer, tidak seperti pada ajaran tertentu dimana untuk mencapai sebuah kesucian tertentu harus meninggalkan kenikmatan dunia, Allah subhanallahuwata'ala berfirman dalam QS. Al-A'raaf ayat 32 :

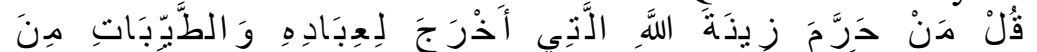

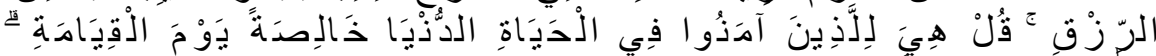

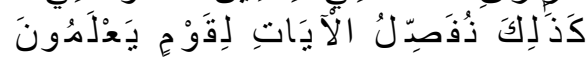

\footnotetext{
${ }^{1}$ Pramono.2012.Analisis pengaruh harga kompetitif, Desain produk, dan layanan Purnajual terhadap minat beli konsumen Sepeda motor Yamaha (studi kasus pada masyarakat kota semarang). Jurnal.
}

Artinya : Katakanlah: "Siapakah yang mengharamkan perhiasan dari Allah yang telah dikeluarkan-Nya untuk hambahamba-Nya dan (siapa pulakah yang mengharamkan) rezeki yang baik?" Katakanlah: "Semuanya itu (disediakan) bagi orang-orang yang beriman dalam kehidupan dunia, khusus (untuk mereka saja) di hari kiamat". Demikianlah Kami menjelaskan ayat-ayat itu bagi orang-orang yang mengetahui.

Berdasarkan latar belakang tersebut, maka penulis tertarik untuk melakukan penelitian untuk melihat minat konsumen dalam jual beli toko Islam dengan mengangkat peran para pelaku usaha ritel dituntut untuk melakukan inovasi yang diharapkan dapat merebut hati konsumen (Achmad, 2011).

Berbelanja merupakan kegiatan yang menyenangkan bagi sebagian orang, karena belanja bukan hanya sebagai aktivitas rutin untuk memenuhi keinginan dan kebutuhan konsumen, tetapi seringkali kegiatan belanja menjadi sarana rekreasi dan hiburan (Achmad, 2010).

Maka peneliti tertarik untuk mengadakan penelitian lebih lanjut mengenai masalah desain (interior dan exterior) yang ada di Toko sakinah Wonorejo. Sehingga muncul permasalahan tentang judul tentang Kosep Desain (eksterior dan interior), excellent service, dan Penetapan Harga Toko yang Bernuansa Islam Mempengaruhi Minat Belanja Konsumen Muslim dalam Kegiatan Perspektif Hukum Ekonomi Syariah di Toko Sakinah Wonorejo Wilayah Surabaya Barat.

Syariah Islam menginginkan manusia mencapai dan memelihara kesejahteraannya. Imam Shatibi menggunakan istilah maslahah, yang maknanya lebih luas dari sekadar utility atau kepuasan dalam terminologi ekonomi konvensional. Maslahah merupakan tujuan hukum syara' yang paling utama. 
Menurut Imam Shatibi, maslahah adalah sifat atau kemampuan barang dan jasa yang mendukung elemen-elemen dan tujuan dasar dari kehidupan manusia di muka bumi ini (Khan dan Ghifari, 1992). Ada lima elemen dasar menurut beliau, yakni: kehidupan atau jiwa (al-nafs), properti atau harta benda (al mal), keyakinan (al-din), intelektual (al-aql), dan keluarga atau keturunan (al-nasl). Semua barang dan jasa yang mendukung tercapainya dan terpeliharanya kelima elemen tersebut di atas pada setiap individu, itulah yang disebut maslahah. Kegiatankegiatan ekonomi meliputi produksi, konsumsi dan pertukaran hyang menyangkut maslahah tersebut harus dikerjakan sebagai suatu religious duty atau ibadah.

Tujuannya bukan hanya kepuasan di dunia tapi juga kesejahteraan di akhirat. Semua aktivitas tersebut, yang memiliki maslahah bagi umat manusia, disebut 'needs' atau kebutuhan. Dan semua kebutuhan ini harus dipenuhi.

Pada tingkat pendapatan tertentu, konsumen Islam, karena memiliki alokasi untuk hal-hal yang menyangkut akhirat, akan mengkonsumsi barang lebih sedikit daripada non-muslim. Hal yang membatasinya adalah konsep maslahah tersebut di atas. Tidak semua barang/jasa yang memberikan kepuasan/utility mengandung maslahah di dalamnya, sehingga tidak semua barang/jasa dapat dan layak dikonsumsi oleh umat Islam. Dalam membandingkan konsep kepuasan dengan pemenuhan kebutuhan (yang terkandung di dalamnya maslahah), perlu membandingkan tingkatan-tingkatan tujuan hukum syara' yakni antara daruriyyah, tahsiniyyah dan hajiyyah. Penjelasan dari masing-masing tingkatan itu sebagai berikut:

1. Daruriyyah,

2. Hajiyyah, Syari'ah

3. Tahsiniyyah
Pertama adalah kebutuhan primer, yakni nafkah-nafkah pokok bagi manusia yang dapat mewujudkan lima tujuan syariat (yakni memelihara jiwa, akal, agama,keturunan dan kehormatan). Tanpa kebutuhan primer kehidupan manusia tidak akan berlangsung. Kebutuhan ini meliputi kebutuhan akan makan, minum, tempat tinggal, kesehatan, rasa aman, pengetahuan dan pernikahan.

Kedua, kebutuhan sekunder, yakni kebutuhan manusia untuk memudahkan kehidupan, agar terhindar dari kesulitan. Kebutuhan ini tidak perlu dipenuhi sebelum kebutuhan primer terpenuhi. Kebutuhan inipun masih berkaitan dengan lima tujuan syariat itu tadi.

Ketiga adalah kebutuhan pelengkap, yaitu kebutuhan yang dapat menciptakan kebaikan dan kesejahteraan dalam kehidupan manusia. Pemenuhan kebutuhan ini tergantung pada bagaimana pemenuhan kebutuhan primer dan sekunder serta, sekali lagi, berkaitan dengan lima tujuan syariat.

Untuk mewujudkan lima tujuan syariat ini, ibu rumah tangga yang umumnya merupakan manajer rumah tangga, mesti disiplin dalam menepati skala prioritas kebutuhan tadi, sesuai dengan pendapatan yang diperoleh suaminya.

Meski satu rumah tangga sudah mampu memenuhi sampai kebutuhan ketiga atau pelengkap, Islam tetap tidak menganjurkan, bahkan mengharamkan pengeluaran yang berlebih-lebihan dan terkesan mewah, karena dapat mendatangkan kerusakan dan kebinasaan. Allah berfirman dalam," (QS al-Israa ayat 16): Dan jika kami hendak membinasakan suatu negeri, Maka kami perintahkan kepada orang-orang yang hidup mewah di negeri itu (supaya mentaati Allah) tetapi mereka melakukan kedurhakaan dalam negeri itu, Maka sudah sepantasnya berlaku terhadapnya perkataan 
(ketentuan kami), Kemudian kami hancurkan negeri itu sehancur-hancurnya".

Adanya kelangkaan satu barang tidak hanya menghadirkan ujian keimanan dan kesabaran seorang manusia. Kelangkaan barang juga akan menuntut seorang hamba untuk kreatif dalam menghasilkan barang dan jasa guna memenuhi kebutuhan hidup sekaligus mencari jalan keluar bagi kesulitan yang dihadapinya. Satu contoh bagaimana manusia mengatasi kelangkaan sumber energi yang dalam beberapa puluh tahun ke depan diperkirakan habis. Banyak penelitian dilakukan untuk menghasilkan sumber energi alternatif. Begitulah, seorang manusia akan lebih terdorong untuk memakmurkan kehidupan masyarakat jika menemukan kesulitan dalam kehidupan ekonomi.

Dalam ilmu ekonomi konvensional tampaknya tidak membedakan antara kebutuhan dan keinginan. Karena keduanya, memberikan efek yang sama bila tidak terpenuhi, yakni kelangkaan. Dinyatakan dalam Imam al-Ghazali tampaknya telah membedakan dengan jelas antara keinginan (raghbah dan syahwat) dan kebutuhan (hajat), sesuatu yang tampaknya agak sepele tetapi memiliki konsekuensi yang amat besar dalam ilmu ekonomi. Dari pemilahan antara keinginan (wants) dan kebutuhan (needs), akan sangat terlihat betapa bedanya ilmu ekonomi Islam dengan ilmu ekonomi konvensional.

Menurut Imam al-Ghazali kebutuhan (hajat) adalah keinginan manusia untuk mendapatkan sesuatu yang diperlukan dalam rangka mempertahankan kelangsungan hidupnya dan menjalankan fungsinya. Kita melihat misalnya dalam hal kebutuhan akan makanan dan pakaian. Kebutuhan makanan adalah untuk menolak kelaparan dan melangsungkan kehidupan, kebutuhan pakaian untuk menolak panas dan dingin. Pada tahapan ini mungkin tidak bisa dibedakan antara keinginan (syahwat) dan kebutuhan (hajat) dan terjadi persamaan umum antara homo economicus dan homo
Islamicus. Namun manusia harus mengetahui bahwa tujuan utama diciptakannya nafsu ingin makan adalah untuk menggerakkannya mencari makanan dalam rangka menutup kelaparan, sehingga fisik manusia tetap sehat dan mampu menjalankan fungsinya secara optimal sebagai hamba Allah yang beribadah kepada-Nya. Di sinilah letak perbedaan mendasar antara filosofi yang melandasi teori permintaan Islami dan konvensional. Islam selalu mengaitkan kegiatan memenuhi kebutuhan dengan tujuan utama manusia diciptakan. Manakala manusia lupa pada tujuan penciptaannya, maka esensinya pada saat itu

\section{PEMBAHASAN}

Awal berdiri bermodal hingga $\mathrm{Rp} 1,2$ Miliar, dengan berjamaah sesama anggota koperasi 212. Ketua Komunitas Koperasi Syariah 212 (KS 212) Surabaya, Eko Yudi Setiawan menyampaikan, pihaknya melakukan grand opening (GO) 212 Mart Subaraya pada Minggu, 27 Agustus 2017, tepatnya di Jalan Wonorejo I No. 46, Manukan-Tendes Surabaya, Jawa Timur.

\section{a. ANGGARAN DAN PEMBIAYAAN MINIMARKET SAKINAH}

Dalam mendirikan 212 Mart Surabaya ini, pihaknya bekerjasama dengan Sakinah Mini Market milik Koperasi Pondok Pesantren Hidayatullah Surabaya, dengan sistem musharakah yaitu bagi hasil 50:50. Tujuan kerjasama ini mengingat untuk mendirikan toko tipe $\mathrm{C}$ ini dibutuhkan dana sebesar $\mathrm{Rp}$ 1,2 miliar. Maka dengan sistem kerjasama ini, pihak komunitas cukup menyediakan dana sebesar Rp 500 juta sudah memiliki 212 Mart lengkap dengan barang-barangnya. Setelah kemudian memiliki dana Rp 500 juta pihaknya mampu mendirikan 212 Mart kedua, begitu seterusnya. 
Adapun sistem bagi hasil, menurut Eko, tentunya sangat normatif sesuai aturan syariah arahan dari KS 212. Yakni, setelah pembagian biaya operasional, pajak, dan zakat. Kemudian secara proporsional pembagian hasil sesuai dengan dana penyertaan dari anggota. Selain itu juga ada bagi hasil sesuai dengan reward transkasi belanja para anggota di gerai 212 Mart, tentu akan berbeda sesuai dengan keaktifan berbelanja.

\section{b. BELANJA DI TOKO MILIK SENDIRI}

Toko sendiri bukan saja nilai ekonomi yang diharapkan meningkat tetapi terpenting adalah kekuatan ibadah memberikan pahala yang diridhoi oleh Allah Subhanallohuwata'ala. Karena ekonomi dan ibadah kuat menjadi pondasi untuk kebangkitan ekonomi umat Muslim Indonesia. Sehingga diharapkan bisa membantu meningkatkan kesejahteraan saudara-saudara Muslim yang ekonominya lemah.

Selain harganya kompetitif juga masyarakat harus sadar bahwa ada nilai perjuangan atau pahala bukan sekadar bisnis. Tujuan didirikan 212 Mart Surabaya ini adalah merasa terpanggil untuk jihad ekonomi. Selama ini masyarakat Muslim hanya menjadi konsumen, dan kini saatnya untuk menjadi pemain atau produsen dalam upaya mengembangkan ekonomi umat, terkhusus lagi ekonomi bangsa.

Maka terinspirasi dari Aksi Damai 212 di Monas Jakarta tahun 2016 lalu, diharapkan spirit tidak kandas tetapi terus bangkit dengan gerakan ekonomi umat. kro dulu, wujudnya adalah 212 Mart perjuangan secara berjamaah omzet 212 Mart Veteran Utama Meroket Rp 20 Juta Perhari

\section{2) Uji Reliabilitas}

Tabel di bawah ini menunjukkan hasil pengujian reliabilitas dengan menggunakan alat bantu SPSS 17.00.

$$
\text { Tabel } 4.9
$$

Hasil Uji Reliabilitas

\begin{tabular}{|l|c|c|c|}
\hline \multicolumn{1}{|c|}{ Variable } & $\begin{array}{c}\text { Cronbach } \\
\text { alpha }\end{array}$ & $\begin{array}{c}\text { Standart } \\
\text { reliabilitas }\end{array}$ & Keterngan \\
\hline $\begin{array}{l}\text { Desain } \\
\text { Eksterior }\end{array}$ & 0,695 & 0,60 & RELIABEL \\
\hline $\begin{array}{l}\text { Desain } \\
\text { Interior }\end{array}$ & 0,714 & 0,60 & RELIABEL \\
\hline $\begin{array}{l}\text { Excellent } \\
\text { service }\end{array}$ & 0,289 & 0,60 & RELIABEL \\
\hline $\begin{array}{l}\text { Penetapan } \\
\text { harga }\end{array}$ & 0,784 & 0,60 & RELIABEL \\
\hline Minat Belanja & 0,854 & 0,60 & RELIABEL \\
\hline
\end{tabular}

Sumber:Hasil Pengolahan Data Kuesioner 2018

Hasil nilai cronbach's alpha variable exterior dan interior dan minat belanja konsumen> 0,60 sehingga indikator atau kuesioner dari ketiga variabel tersebut reliabel atau layak dipercaya sebagai alat ukur variabel.

\section{e. Uji Asumsi Klasik}

1) Uji Normalitas Data

Pengujian Normalitas digunakan untuk menguji apakah dalam sebuah model regresi, variabel terikat, variabel bebas atau keduanya mempunyai distribusi normal ataukah tidak. Model regresi yang baik adalah distribusi data normal atau mendekati normal. Hasil uji Normalitas dapat dilihat pada gambar dibawah : Gambar 4.7

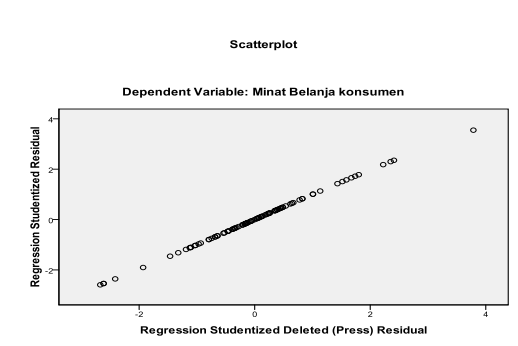


Sebagaimana terlihat dalam grafik Normal P-P plot of regression Standardized Residual, terlihat bahwa titik - titik menyebar disekitar garis diagonal, serta penyebarannya mengikuti arah garis diagonal (membentuk garis lurus ), maka dapat dikatakan bahwa data berdistribusi normal dan model regresi layak dipakai untuk memprediksi minat belanja konsumen berdasarkan variabel bebasnya.

2) Uji Multikolinieritas Data

Uji multikolinieritas perlu dilakukan untuk menguji apakah pada model regresi ditemukan adanya korelasi antar variabel bebas, jika terjadi korelasi, maka dinamakan terdapat problem Multikolinieritas (MULTIKO). Untuk mengetahui multikolinieritas antar variabel bebas tersebut, dapat dilihat melalui VIF (variance inflation factor) dari masing-masing variabel bebas terhadap variabel terikat. Apabila nilai VIF tidak lebih dari 5 berarti mengindikasi bahwa dalam model tidak terdapat multikolinieritas.Santoso (2002:206) mengemukakan besaran VIF (variance inflation factor) dan Tolerance, pedoman suatu model regresi yang bebas multiko adalah :

a. Mempunyai nilai VIF disekitar angka 1

b. Mempunyai angka TOLERANCE mendekati 1

Tabel 4.10

Hasil Uji Multikolinieritas Variabel Bebas

\begin{tabular}{|c|c|c|c|}
\hline $\begin{array}{c}\text { Variabel } \\
\text { Bebas }\end{array}$ & Tolerance & VIF & $\begin{array}{c}\text { Keputusan } \\
\text { terhadap } \\
\text { Asumsi } \\
\text { Multikolinierit } \\
\text { as }\end{array}$ \\
\hline $\begin{array}{c}\text { EXTERIO } \\
\text { R (X1) }\end{array}$ & 0.431 & $\begin{array}{c}2.31 \\
9\end{array}$ & $\begin{array}{c}\text { Cukup } \\
\text { Terpenuhi }\end{array}$ \\
\hline
\end{tabular}

\begin{tabular}{|l|c|c|c|}
$\begin{array}{l}\text { INTERIO } \\
\mathrm{R}(\mathrm{X} 1)\end{array}$ & 0.431 & $\begin{array}{c}2.31 \\
9\end{array}$ & $\begin{array}{c}\text { Cukup } \\
\text { Terpenuhi }\end{array}$ \\
\hline $\begin{array}{l}\text { Excellent } \\
\text { service } \\
\text { (X2) }\end{array}$ & 0,829 & 2.31 & \\
\hline $\begin{array}{l}\text { Penetapan } \\
\text { harga (X3) }\end{array}$ & 0,798 & 9 & Cukup \\
Terpenuhi
\end{tabular}

Sumber:Hasil Pengolahan Data Kuesioner 2018

Pada tabel 4.8 di atas terlihat bahwa kedua variabel bebas sebagian besar memiliki besaran angka VIF di sekitar angka 1 (Exterior $=2.319 ; \quad$ Interior $=2,319)$, besaran angka Tolerancesebagian besar mendekati angka 1 (Exterior $=0,431$; Interior $=0,431$ ), sehingga dapat disimpulkan bahwa tidak terjadi Multikolinieritas antara keduavariabel bebas dan model regresi layak digunakan.

3) Uji Heteroskedastisitas

Tujuan dari pengujian ini adalah untuk menguji apakah dalam sebuah model regresi, terjadi ketidaksamaan varians dari residual dari satu pModel regresi yang baik adalah tidak terjadi Heteroskedastisitas. Hasil pengujian ditunjukkan dalam gambar 4.10 berikut :

Gambar 4.10

Grafik Uji Heteroskedastisitas

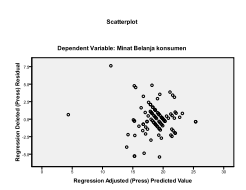

Dari grafik Scatterplot tersebut, terlihat kebanyakan titik titik menyebar secara acak pada angka antara -2 sampai 2 , serta tersebar baik diatas maupun dibawah angka 0 pada sumbu Y. Hal ini 
berarti tidak terjadi heretoskedastisitas pada model regresi, sehingga model regresi layak dipakai untuk memprediksi minat belanja konsumen berdasar masukan variabel independent-nya.

f. Analisis Regresi Berganda

Analisis regresi berganda digunakan untuk mengetahui pengaruh antara variabel independen terhadap variabel dependen, sekaligus untuk melihat hasil pengujian hipotesis yang diajukan. Hasil regresi antara Pengaruh desain (eksterior dan interior), excellent service dan penetapan harga toko terhadap minat belanja konsumen pada toko Sakinah dapat dilihat hasilnya sebagai berikut:

Dalam penelitian ini digunakan hasil uji regresi yang standardized dikarenakan untuk menyamakan ukuran variabel independen (exterior dan interior), excellent service, dan penetapan harga yang tidak sama. Keuntungan menggunakan hasil regresi yang standardized yaitu mampu mengeliminasi perbedaan untuk ukuran pada variabel independen. Selain itu hasil uji regresi yang standardized digunakan karena ingin melihat tingkat priroritas(Hardian Hanggadhika, 2010).

Dari tabel diatas dapat diperoleh persamaan regresi linear berganda sebagai berikut:

$$
\mathrm{Y}=0,330 \mathrm{X} 1+0,522 \mathrm{X} 1+0,268 \mathrm{X} 2+(-1,33) \mathrm{X} 3
$$

Konstanta sebesar $-0,652$ artinya jika desain (exterior dan interior), excellent service, penetapan harga nilainya adalah 0 , maka minat belanja konsumen $(\mathrm{Y})$ nilainya sebesar0,652.

Koefisien regresi variabel desain eksterior (X1) sebesar 0,330; artinya jika variabel independent lain nilainya 0 dan eksterior (X1) mengalami kenaikan 1 satuan, excellent service (X2) sebesar 0,268 ; artinya jika variabel independent lain nilainya 0 dan penteapan harga sebesar $(-1,33)$ mengalami kenaikan 1 satuan maka minat belanja konsumen (Y) akan mengalami kenaikan sebesar 0,330 . Koefisien bernilai positif artinya terjadi hubungan positif antara variabel exterior (X1), excellent service (X2) dengan minat belanja konsumen $(\mathrm{Y})$.

Koefisien regresi variabel desain interior $(X 1), 0,522(X 2)$ sebesar 0,268; artinya jika variabel independent lain nilainya 0 dan penteapan harga sebesar $(-1,33)$; artinya jika variabel independent lain nilainya 0 dan desain interior (X1) mengalami kenaikan 1 satuan, maka minat belanja (Y) akan mengalami kenaikan sebesar 0,522 . Koefisien bernilai positif artinya terjadi hubungan positif antara variabel desain interior (X1) dengan minat belanja konsumen (Y).sedangkan penetapan harga (X3) bernilai negatif maka terjadi hubungan negatif.

\section{g. Koefisien Determinasi $\left(\mathbf{R}^{2}\right)$}

Pada tabel 4.12 menunjukkan nilai adjusted $\mathrm{R}^{2}$ sebesar 0,633 , hal ini berarti seluruh variabel desain (eksterior dan interior), excellent service, penetapan harga mempunyai kontribusi secara bersama-sama sebesar 63,3\% terhadap variabel terikat (Y) yakni minat belanja konsumen. Sisanya sebesar $36,7 \%$ dipengaruhi oleh faktor-faktor dari pengaruh variabel lain yang tidak masuk dalam penelitian.

Standard Error of The Estimate (SEE) dari tabel diatas sebesar 2,044. Semakin kecil nilai SEE, maka akan membuat persamaan regresi semakin tepat dalam memprediksi variabel dependen.

\section{a. Uji Simultan F}

Uji serempak atau uji $\mathrm{F}$ merupakan uji secara bersama-sama untuk menguji sigifikansi pengaruh variabel Exterior dan Interior (X1) secara bersama-sama terhadap variabel minat belanja konsumen (Y). Uji F dilakukan dengan membandingkan Fhitung dengan Ftabel. Hasil Uji F bisa dilihat pada tabel 4.13 berikut ini:

Berdasarkan hasil uji simultan, tabel 4.13 menunjukkan bahwa Fhitung sebesar 86,383; sedangkan hasil Ftabel pada tabel distribusi dengan tingkat kesalahan 5\% dengan hasil perhitungan df1 
$(\mathrm{N} 1)=2$ dan $\mathrm{df} 2(\mathrm{~N} 2)=97$ menunjukkan Ftabel $=3,44$. Hal ini berarti Fhitung > Ftabel $(86,383>3,44)$. Nilai signifikansi lebih kecil dari 0,05 . Perhitungan tersebut menunjukkan bahwa seluruh variabel turunan desain (eksterior dan interior) (X1), excellent service (X2), dan penetapan harga (X3) secara bersama-sama mempunyai pengaruh yang positif dan signifikan terhadap variabel minat belanja konsumen ( $\mathrm{Y}$

Variabel desain (Eksterior dan Interior) (X1). Berdasarkan tabel 4.14 nilai t hitung untuk variabel exterior sebesar 3,559. Sementara itu nilai pada tabel distribusi 5\% sebesar 1,980. Maka $\mathrm{t}$ hitung $(3,559)>\mathrm{t}$ tabel $(1,980)$ dan nilai signifikansi $(0,000<$ 0,050), sehingga $\mathrm{H} 1$ yang berbunyi ada pengaruh positif dan signifikan antara exterior dengan minat belanja konsumen di toko Sakinah diterima. Sedangkan H0 yang berbunyi tidak ada pengaruh positif dan signifikan antara exterior dengan minat belanja konsumen di toko Sakinah ditolak, berarti variabel exterior (X1) berpengaruh positif dan signifikan terhadap variabel keputusan pembelian (Y).

Berdasarkan tabel 4.16 nilai $\mathrm{t}$ hitunguntuk variabel ini sebesar 5,625. Sementara itu nilai pada tabel distribusi 5\% sebesar 1,980. Maka t hitung $(5,625)>\mathrm{t}$ tabel $(1,980)$ dan nilai signifikansi $(0,004<0,050)$, sehingga H1 yang berbunyi ada pengaruh positif dan signifikan antara interior dengan minat belanja konsumen di toko Sakinah diterima. Sedangkan H0 yang berbunyi tidak ada pengaruh positif dan signifikan antara variabelinterior dengan minat belanja konsumendi toko Sakinah ditolak, berarti variabel desain interior (X1) berpengaruh positif dan signifikan terhadap varibel keputusan pembelian (Y).

\section{ANALISIS PENELITIAN}

Dengan demikian dapat diketahui bahwa untuk menarik konsumen untuk beli terdapat faktor-faktor lain selain variabel (eksterior dan interior), excellent service, dan penetapan harga yang mempengaruhi minat belanja konsumen di toko Sakinah. Perangsangan minat belanja konsumen berupa komponen komponen desain (eksterior dan interior), excellent service, dan penetapan harga lah yang terbukti memang masih dominan.

Dari hasil penelitian kuesioner tentang excellent service yang didapatkan dengan nilai rata - rata terendah terdapat pada indikator kedua sebesar $(3,87)$, yaitu pelayanan ditoko sakinah sangat ramah. Berarti dapat disimpulkan bhawa konsumen belum merasa nyaman dengan pelayanan yang diberikan oleh toko sakinah. Pada indikator pelayanan ditoko sakinah tanggap dan cepat sebesar $(3,95)$, hal ini dapat dismpulkan bahwa konsumen merasa senang dengan pelayanan ditoko 75. Untuk indikator yang menyatakan bahwa kondisi ditoko sakinah rapi dan bersih sebesar $(3,96)$, dapat disimpulkan bahwa kerapihan dan kebersihan sangatlah diutamakan oleh toko sakinah. Sedangkan yang mempunyai nilai tertinggi terdapat pada indikator keempat $(3,98)$, yaitu toko sakinah sangat nyaman. Karena konsumen merasa nyaman dengan fasilitas yang disediakan oleh toko sakinah, seperti tempat duduk untuk menunggu atau mencoba produk.

Hasil penelitian ini sesuai dengan hasil penelitian yang telah dilakukan oleh Weenas (2013) yang membuktikan bahwa kualitas pelayanan berpengaruh positif dan signifikan terhadap minat.

1. Berdasarkan analisis regresi diketahui bahwa koefisien regresi exterior sebesar 0,330 dan interior sebesar 0,522; excellent service sebesar 0,268 dan penetapan harga -1,33 maka dapat dikatakan bahwa ada variabel yang berpengaruh dan ada yang tidak berpengaruh secara signifikan terhadap minat belanja konsumen. Dari hasil - hasil tersebut dapat diketahui bahwa variabel yang paling dominan mempengaruhi minat belanja konsumen dalam melakukan pembelian pada toko Sakinah adalah variabel interior dengan koefisien sebesar 0,522, dan variabel penetapan harga $-1,33$ yang tidak begitu dominan berpengaruh 
terhadap minat belanja konsumen adalah variabel exterior dengan koefisien sebesar 0,330 dan excellent service sebesar 0,268 .

2. Berdasarkan pengolahan data kuisioner dengan menggunakan metode penentuan range yang diperoleh dari para responden menunjukkan mayoritas responden setuju bahwa tampilan desain (exterior dan interior) pada toko Sakinah telah sesuai dengan nilai-nilai islam, dengan perolehan nilai indeks pada tampilan exterior 386 dan nilai indeks pada tampilan interior sebesar 387 yang menunjukkan tinggi.

\section{PENUTUP}

Maka diperoleh dari hasil penelitian pengaruh desain ( exterior dan interior), Excellent service, Penetapan Haraga toko terhadap minat belanja konsumen pada konsumen adalah sebagai berikut:

Berdasarkan nilai koefisien determinasi menunjukkan nilai adjusted $\mathrm{R}^{2}$ sebesar 0,633 , hal ini berari seluruh variabel desain (exterior dan interior) mempunyai kontribusi secara bersama-sama sebesar $63,3 \%$ terhadap variabel terikat $(\mathrm{Y})$ yakni minat belanja konsumen. Sisanya sebesar $36,7 \%$ dipengaruhi oleh faktor-faktor lain yang tidak masuk dalam penelitian.

Dari hasil penelitian ini, faktor yang mempengaruhi keputusan pembelian terakhir adalah kualitas pelayanan. Berdasarkan pertanyaan tentang kenyamanan ditoko sakinah yang dirasakan oleh konsumen. Pelayanan dan kenyamanan yang diberikan toko sakinah dinilai baik oleh konsumen namun belum berdampak besar dalam mempengaruhi minat beli. Maka peneliti menyarankan untuk lebih meningkatkan kualitas pelayanan dan kenyamanan di toko sakinah, dengan cara memberikan fasilitas ruang tunggu atau shofa yang nyaman untuk pelanggan yang sedang mencoba sakinah. Dengan demikian, pelanggan akan merasa diperhatikan dan senang melakukan pembelian ualng di toko sakinah

\section{DAFTAR PUSTAKA}

Amirullah.Perilaku Konsume. Graha Ilmu. Yogyakarta.2002.

Anto Danjan, .Pengantar Metode Statistik Jilid I. Pustaka LP3ES Indonesia, anggota IKAPI. 1986.

Ma'ruf, Hendri. Pemasaran Ritel. Gramedia Pustaka, Jakarta. 2006.

Ardi Irawan, Achmad. Analisis Pengaruh Store atmosphere Terhadap Keputusan Pembelian Pada Konsumen Gyant Hypermarket, Mall Olimpic Garden Malang. Skripsi. Ekonomi-S1, Fakultas Ilmu Administrasi, Universitas Brawijaya, Malang. 2010.

Foster,Bob, Analisis Bauran Penjualan Ritel (Ritel Mix) Depatement StoreDi DKI Jakarta. Desertasi, Ekonomi-S3, Fakultas Ekonomi, Universitas Informatika dan Bisnis Indonesia, Bandung.2010.

Eko Putra, Nandi, Analisis Pengaruh Suasana Toko (Store atmosphere) dan Lokasi terhadap Minat Beli Konsumen pada Wedezic Distro Kota Padang (Studi Pada Mahasiswa S1 Universitas Brawijaya Malang. Skripsi, Ekonomi-S1, Fakultas Ekonomi, Universitas Andalas, Padang.2011.

Sulistiyawan, Fauzan. Pengaruh Retailing Mix Terhadap Keputusan Pembelian Pada Alfamart Di Jl.Gajayana Malang. Skripsi, Ekonomi-S1, Fakultas Ekonomi, Universitas Islam Negeri, Malang. 2008

Suprapti, Lilik. Analisis Pengaruh Brand Awareness, Perceived Value, Organizational Association dan Perceived Quality terhadap Keputusan Pembelian Konsumen. Skripsi, 
Ekonomi-S1, Fakultas Ekonomi, Universitas Diponegoro,

Semarang. 2010.

Swasta, Basu. Manajemen Pemasaran. BPFE Yogyakarta.2003.

Umar, Husein. Riset Pemasaran Dan Perilaku Konsumen. PT Gramedia Pusaka Utama, Jakarta. 2000.

Yusanto, Ismail M dan Widjajakusuma, Karebet. Menggagas Bisnis Islam. Gema Insani Press, Jakarta. 2000.

Nurahman, Deni. Analisis Bauran Eceran (Retailing Mix) Pada No Label Stuff Clothing Bandung. Skripsi. Ekonomi-S1, Fakultas Ekonomi, Universitas Komputer Indonesia, Bandung. 2007. 